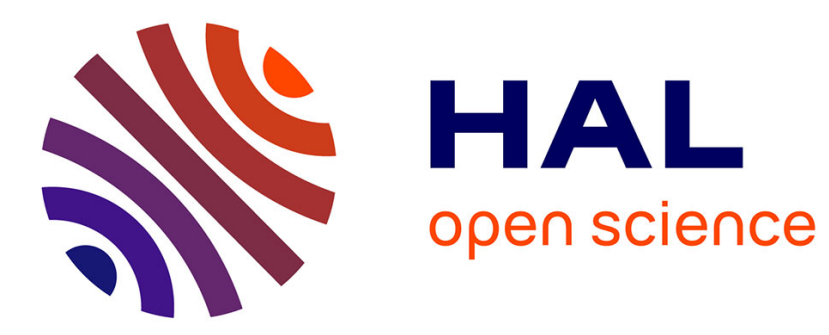

\title{
POPULATION DENSITIES OF TRIPLET EXCITED STATES IN A DIFFUSE NITROGEN PLASMA
}

\author{
Arif Ashraf, U. Roychowdhury, P.K. Ghosh
}

\section{To cite this version:}

Arif Ashraf, U. Roychowdhury, P.K. Ghosh. POPULATION DENSITIES OF TRIPLET EXCITED STATES IN A DIFFUSE NITROGEN PLASMA. Journal de Physique Colloques, 1979, 40 (C7), pp.C7-129-C7-130. 10.1051/jphyscol:1979763 . jpa-00219469

\section{HAL Id: jpa-00219469 https://hal.science/jpa-00219469}

Submitted on 1 Jan 1979

HAL is a multi-disciplinary open access archive for the deposit and dissemination of scientific research documents, whether they are published or not. The documents may come from teaching and research institutions in France or abroad, or from public or private research centers.
L'archive ouverte pluridisciplinaire HAL, est destinée au dépôt et à la diffusion de documents scientifiques de niveau recherche, publiés ou non, émanant des établissements d'enseignement et de recherche français ou étrangers, des laboratoires publics ou privés. 
POPULATION DENSITIES OF TRIPLET EXCITED STATES IN A DIFFUSE NITROGEN PLASMA*

\author{
A. Ashraf, U.K. Roychowdhury ${ }^{+}$and P.K. Ghosh. \\ Department of Chemistry, Indian Institute of Technology Kanpur, Kanpur 208016 India.
}

Recently there has been much activity on line emission studies from nitrogen plasmas $(1-5)$, primarily due to their relevance in understanding of upper atmospheric emission. But hitherto there has been iittle experimental work which investigates the nature of quantitative correlation between the population densities of excited states in laboratory nitrogen plasmas and cross sections of relevant electron impact processes. However, such investigations to be amenable to quantitative correlations with atomic processes, values of plasma parameters must directly be known. This is not available from earlier laboratory plasma experiments. Here we report the results ofan experiment in which in situ measurements of electron densities $\left(n_{e}\right)$ and electron temperatures $\left(T_{e}\right)$ were carried out besides vibronic and rotational transition intensities from a nitrogen plasma.

Experiments were conducted at a pressure of 5 microns in a $90 \mathrm{~cm}$ long $2.5 \mathrm{~cm}$ diameter stainless steel tube and the plasma sustain ed by electrons injected from one end of the tube, at plasma currents ( $I_{E}$ ) of $0.5,1$ and 2 amps. The plasma was immersed in a longitudinal magnetic field ( $B=0-700$ gauss). Variation of the magnetic field resulted in a coupled variation of ne and te measured at the centre of the plasma column by means of a Langmuir probe. Results of the se measurements are shown in Fig. 1. The radiation from the axial region of the plasma column was taken to a $2.1 / 6.3$ meter spectrograph (first order dispersion $3.4 \mathrm{~A}$ per mm/1.12A per $\mathrm{mm}$ ) through a set of angle limiting baffles. Relative intensities from the $\mathrm{N}_{2}$ COI $\pi_{\mathrm{s}}$ state (second positive system SPS) were measured. A typical vibrational temperature Tvib plot and vibrational temperatures determined from band head intensities in the ne, $T_{e}$ range of the experiment are shown in Fig.2 and Table 1 respectively. For all the SPS bands, $T_{y}$ increases with increase of $B$. In general, at a given $B$, it increases with $\mathrm{I}_{\mathrm{E}}$.

High resolution rotational spectra of SPS vibronic bands $(1,0),(0,2)$ were photographed in 3 rd order of the 6.3 meter mode of the spectrograph, and relative intensities

Table 1. Vibrational Temperatures of the $C^{3} \pi_{u}$ state from the $(0-2)$ sequence of the Second Positive System

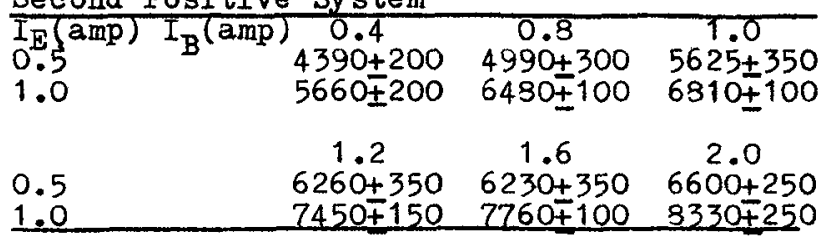

measured using a microdensitometer. Rotational temperatures of the ground vibrational state at $I_{E}=1$ amp are shown in Table 2 .

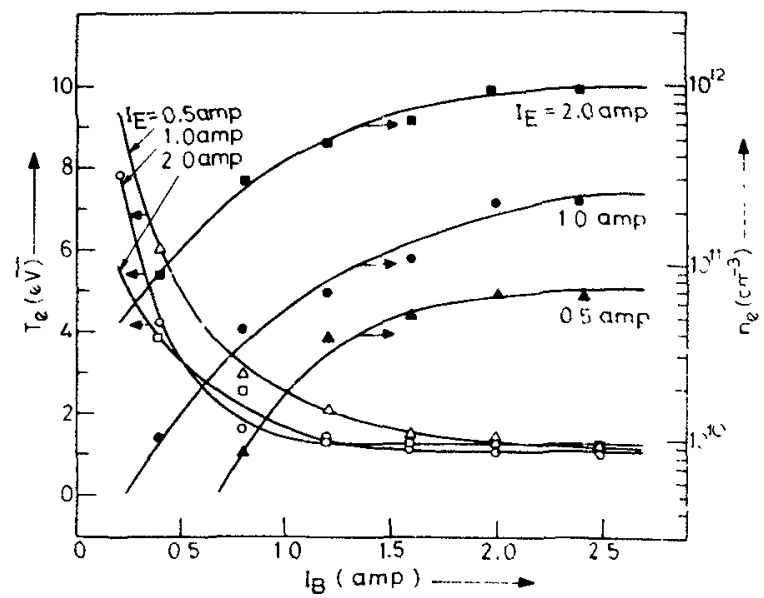

Fig.1 Plasma parameters in the magnetic field $\left(I_{B}=\right.$ magnet current; $B=280$ gauss/amp of $\left.I_{B}\right)$

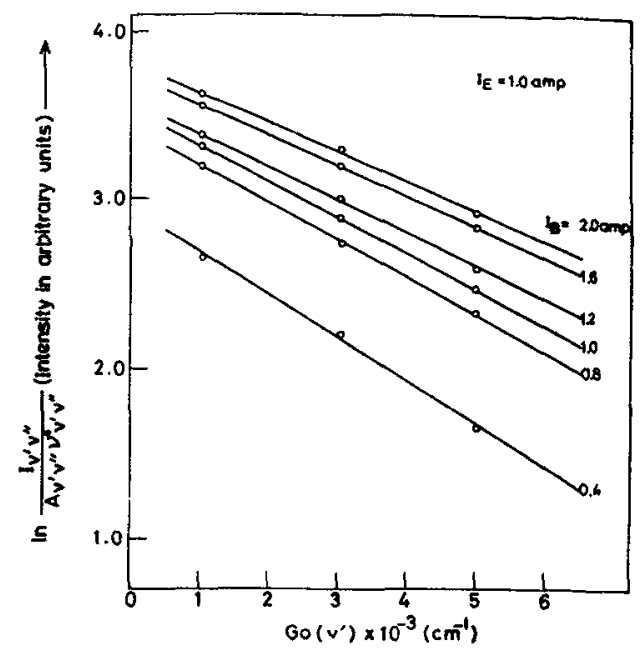

Fig.2.Vibrational temperature plot from the $\mathrm{N}_{2}(0-2)$ band sequence of the Second Positive System

Table 2. Rotational Temperatures of the Ground Vibrational state of $\mathrm{C}^{3} \mathrm{M}_{\mathrm{m}}$

\begin{tabular}{|c|c|c|c|}
\hline$I_{B}(a m p)$ & 0.5 & 7.5 & 2.0 \\
\hline$R_{0}$ & $620 \pm 20 \quad 655 \pm 20$ & $630 \pm 20$ & $610 \pm 20$ \\
\hline$R_{1}$ & $6: 5 \pm 20 \quad 690 \pm 20$ & $720 \pm 20$ & $600 \pm 20$ \\
\hline $\mathrm{R}_{2}$ & $620 \pm 20 \quad 695 \pm 20$ & $745 \pm 20$ & $620 \pm 20$ \\
\hline
\end{tabular}


In the following sections we show the role of various processes in the total cross section by choosing the example of the $B$ state, and also report results of calculations of population densities of the $\mathrm{N}_{2}$ triplet excited states.

The total cross section of the $B^{3} \pi_{g}$ is shown in Fig. 3 for the vibrational levels $\mathrm{v}=0-11$ with electron energy as a parameter. The cross sections are evaluated using the method from (6) and using the processes: electron impact excitation $X^{\prime} \Sigma_{g}^{+}\left(v^{\prime \prime}=0\right)-B^{3} \Pi_{g}\left(v^{\prime}=\right.$

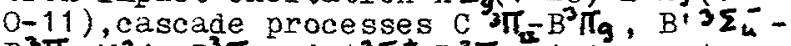
$B^{3} \pi_{g}, W^{3} \Delta_{u}-B^{3} \pi_{g}$ and $A^{3} \Sigma_{u}^{*}-B^{3} \pi_{g}$ intersystem cascade. One notes a strong dependence of the cross section on the electron energy for the lower vibrational states, unlike the higher ones. Enhanced population densities are observed beyond the $\mathrm{v}=9$ level. Direct electron impact excitation from the ground state, $C^{3} \pi_{u}-B^{3} \pi_{g}$, as well as $B^{13} \Sigma_{u}^{-}-B^{3} \pi_{g}$ contribution decrease with increasing vibrational quantum number of the $B^{3} \pi_{g}$ state, and $W^{3} \Delta_{u}-B^{3} \pi_{q}$ contribution is negligible. It is the $A^{3} \Sigma_{u}^{+}-B^{3} \pi_{g}$ intersystem cascading which increases with the vibrational quantum number of the $B^{3} \pi_{g}$ state and accounts for increased population densities of the $B^{3} \pi_{9}$ vibrational states beyond $\mathrm{V}=9$. Fig.4 shows the partial contributions of the various processes to the $B^{3} \Pi_{g} v=2$ state, the state which has the highest Franck-Cond on factor with respect to the ground state.

The collisional-radiative model used in calculation of population densities of triplet states involves the following: the ground vibrational state $v=0$ of the $X^{\prime} \Sigma+$ state, $v i b-$ rational levels $0-11$ of $A^{3} \sum_{h}^{+}, v=0-12$ of $B^{3} \pi_{g}$, $v=0-7$ of $W^{3} \Delta_{k}, v=0-12$ of $B^{3} \sum_{u}^{2}$ and $v=0-3$ of $\mathrm{C}^{3} \Pi_{\mu}$. The following electron impact processes are considered: $X^{\prime} \Sigma_{g}^{+}-A^{3} \Sigma_{L}^{+},-B^{3} \pi_{9}$, $-C^{3} \pi_{u_{p}}-W^{3} \Delta_{u_{1}}-B^{3} \Sigma_{n}^{-}$, radiative transitions $C^{3} \pi_{u}-B^{3} \pi_{g}, B^{3} \pi_{g}-A^{3} \sum_{u}^{+}, B^{13} \sum_{u}^{-}-B^{3} \pi_{g}, W^{3} \Delta_{u}-B^{3} \pi_{g}$, and $\mathrm{A}^{3} Z_{4}^{+}-\mathrm{X}^{1} \Sigma_{0}^{+}$besides intersystem cascades $B^{3} \Pi_{g}-B^{13} \Sigma_{u}^{-}, A^{3} \Sigma_{u}^{ \pm}-B^{3} \Pi_{g}, B^{3} \Pi_{g}-W^{3} \Delta_{u}$. The total electron impact cross sections are from (7), the method of obtaining vibrational cross sections from electronic state cross sections is from (6), and the Franck-Condon factors of various states are from $(6,8,9)$, and transition probabilities from $(10-12)$. The population densities calculated numerically using steady state condition, Maxwellian velocity distribution of electrons, and a constraint that the sum of population densities of all the states is equal to $1.6 \times 10^{14} \mathrm{~cm}^{-3}$, are shown in Fig.5. It will be noted that the $C$ state vibrational levels do not thermalize, in variance with experimental results.

References

1. F.Cramarossa et al, JQSRT 14,419(1974)

2. A.M.Bouchoux et al, JQSRT $\frac{16}{16}, 451$ (1976)

3. J.C.Georges, J.Phys.B 9,2153 (1976)

4. D.C.Cartwright, J.Ge op hys. Re s. $93,517(1978)$

5. D.C.Cartwright,J.Appl.Phys .49,3855 (1978)

6. W.L.Borst et al, J.Chem.Phys. 599,5830 (1973)

7. D.C.Cartwright etal, Phys.Rev.A 16, 1041 (1977)

3. K.A.Saum et al, Phys.Rev.A2,1655(1970)

9. W.Benesch et aI,Ap.J.143,236(1966)

10.K.Covey et al, J.O.S.A.63,592(1973)

11.D.E.Shemansky et al, JQSRT 11,1385(1971)

12.D.E. Shemansky, J.Chem.Phys.51,689(1969)

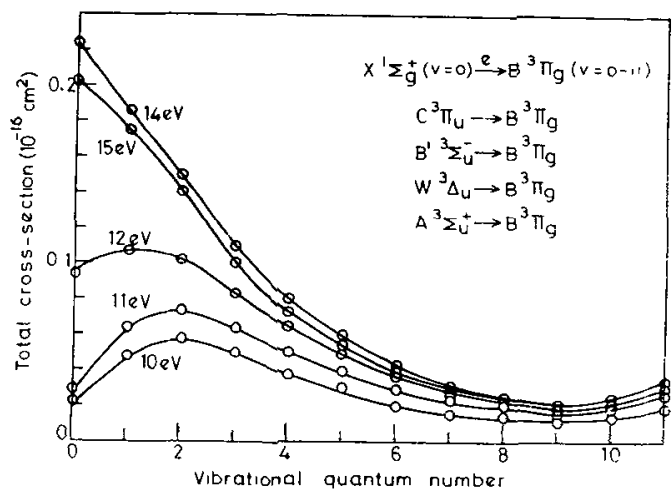

Fig.3 Total cross section of $B^{3} \pi_{9}$

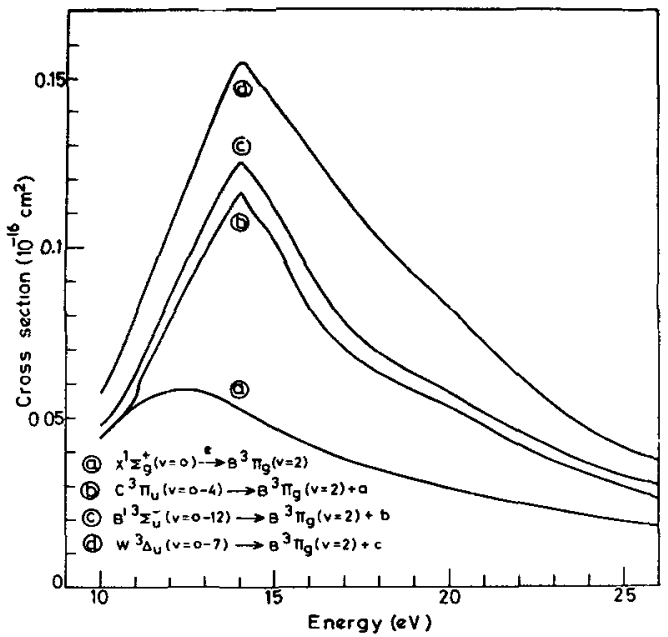

Fig.4 Partial contributions to $B^{3} \pi_{g}(v=2)$

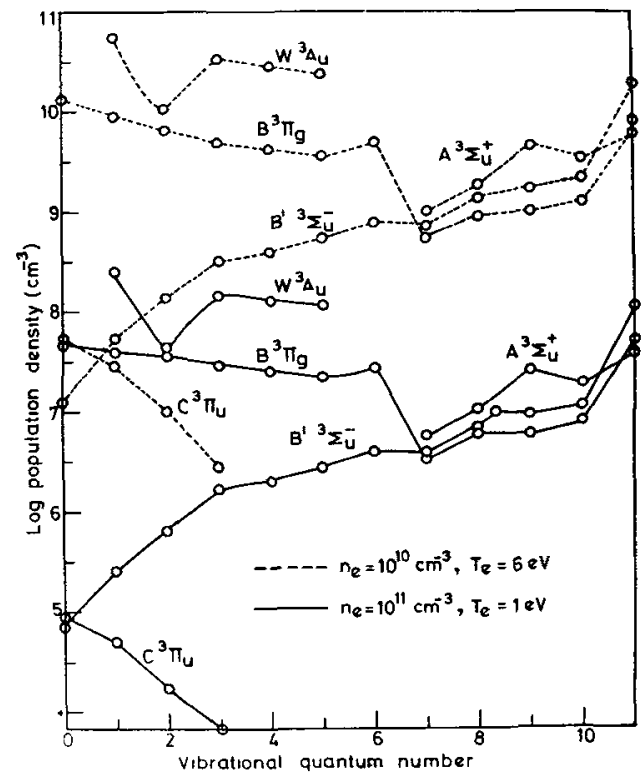

Fig.5 Population densities of $\mathrm{N}_{2}$ triplet states for total particle density $1.6 \mathrm{x}$ * Supported by the Dept. of Atomic Energy + Present Address: Dept. of Chemistry, Western Illinois University, Macomb, IL,U.S.A. 